\title{
15
}

\section{AFFORDABLE HOUSING AND DESIGN INNOVATION}

\author{
A View from Paris
}

Christelle Avenier and Sasha Tsenkova

\section{Design Quality in Affordable and Social Housing}

Decent, affordable housing is critical to the social and economic well-being of any nation. Different housing systems respond to this challenge in different ways. In countries with more diverse housing systems, sustained investment in social, non-market housing continues to provide significant additions to the stock to address affordability challenges and the needs of lowincome residents. A number of European countries fall in this category where a diversity of housing providers - public, private and non-profit - operate with substantial government support to finance, build and manage affordable/social housing allocated on the basis of need (Tsenkova, 2019). France is a country where such long-term commitment is supported by urban policies for social inclusion, social mix and inclusive neighbourhood redevelopment. While the need for such housing continues to outstrip supply, particularly in large cities, the social housing projects, being built aim to promote design excellence, create places of community interaction that meet the needs of residents, but also allow them to live with pride and dignity, avoiding physical and social isolation. Good-quality design —often considered an expensive amenity in many other countries with more restrictive housing policies-is promoted through design competitions for social housing projects and programme requirements that allow developments to integrate successfully in the neighbourhood and contribute to its evolving urban fabric. The result is a country dotted with projects that meet and exceed affordable housing requirements and raise the bar in terms of well-planned, well-designed environments. This approach is a departure from the strategies of mass-produced social housing in high-density peripheral housing estates that dominated the social housing developments of the 1960s and 1970s, not just in France but also in many other European countries (Tsenkova, 2014).

Good design in recent housing policies in France, but also globally, is considered to be a critical component for successful social housing development essential for its residents and the community where it is built for years to come. Good design may be the most viable strategy available to improve the quality, functionality, asset value and acceptance of affordable housing. The literature articulates the value of good design principles to address issues of higherdensity, appropriate construction materials, building massing and siting strategies. Good design is considered essential; it is much more than aesthetics and a process much more than a product 
defined by innovation, expertise, community engagement and user/client feedback (Evans and Beck, 2005). Studies posit that the goal of a good design process is to create developments that (1) meet the needs of the occupants, (2) respond to the building's physical context, (3) enhance their neighbourhoods and (4) are built to last. A number of sustainability design guidelines provide case studies of affordable and social housing developments that are both well-designed and green incorporating environmental and social features. New Jersey Institute of Technology (2003) highlights ten criteria that can be used, such as community context, site design, building design, water conservation and management, energy efficiency and indoor environmental quality. "Designing New York: Quality Affordable Housing" (2018) lays out best practices in planning affordable housing that contribute to the quality, character, diversity and experience of New York City's communities while improving equity and sustainability for residents and neighbourhoods. The developments should foster density and encourage interaction while presenting inviting, warm, safe and dignified living spaces that are durable, easy to maintain, attractive and accessible by transit.

\section{Design Strategies for Affordable Housing}

The following design strategies are identified for the successful development of affordable housing and its integration in the neighbourhood:

\section{Create Synergies of Uses}

Many affordable and social housing developments serve people that need extra support, such as seniors, formerly homeless individuals or low-income families. Creative use of space, careful attention to architectural detail and thoughtful integration of open spaces, common areas and public art can make a huge difference in the experience and perception of a building.

Projects need to be designed inside-out and outside-in. A strong relationship between community rooms and individual housing units is important. Ensuring that the development provides opportunities for social interaction, community events that can spill out in the courtyard or sidewalk can enhance social activities and help residents feel part of the local community. Incorporating amenities, such as day care, community centres, urban gardens, small-scale retail and business premises at the ground level, can provide an important catalyst for local economic development and integration.

\section{Reweave and Integrate in the Urban Fabric}

Affordable housing projects in the past were often isolated from the rest of the city, which often created stigma and exclusion. Good design requires new developments to be 'knit into the urban fabric' so residents have access to transportation, jobs and all community resources. It means that projects in such attractive locations with high land value might have higher density, so a focus on building massing, access and circulation is particularly important to contextualize the design.

An understanding of the orientation and nature of the nearby urban typologies is key to successful integration in the urban landscape (Prevost et al., 2015). Projects should connect to existing typologies and use materials and style that contextualize and enhance integration in the streetscape and the neighbourhood. The design could orient views strategically, perhaps to a nearby landmark or public park, "borrowing" green space or visually connecting interior courtyard or community room which can create a more animated pedestrian realm (Baker and Patel, 2015). 


\section{Design Flexible Housing Spaces}

Affordable housing is often built with constrained budgets for people with a variety of housing needs. It is important to consider the social aspects, changing life circumstances and needs and provide thoughtful design solutions that allow people to age in place, adjust to changing lifestyles and health challenges while remaining in the place they call home. Flexibility of individual units is a socially and economically efficient way of designing social housing. This may include diversity of housing types to allow a transition through a continuum of units with various supports, accessible design considerations and specific requirements related to the design of kitchens, bathrooms and balconies.

\section{Implement Sustainable Design + Form}

The first step to provide an efficient concept for sustainable and affordable housing is through optimal architectural design (Praznik, Butala \& Zbašnik-Senegačnik, 2014). The architectural design process involves considering all factors that influence a specific site and performing background research to determine the best possible solution or design. When considering sustainable design, the research phase of the design process will determine where the building should be placed on the site to ensure optimal sun exposure, connectivity, passive air circulation and minimal impacts to existing landscapes (Martty, 2015). Affordable housing design should survive the test of time and remain a positive feature/landmark in the neighbourhood.

\section{Select Green Materials + Assemblies}

Once the site and mass of the housing is determined, materials then need to be sourced and building assemblies need to be detailed as we move forward to a more sustainable future (Rothrock, 2014). Green strategies for affordable housing promote the use of materials that are local, renewable, recycled or that have specific life-cycle assessment ratings (Canadian Mortgage and Housing Corporation, 2016). The way that materials are assembled in the building can also have an impact on the efficiency of the housing and contribute to passive efforts supported by the envelope design. Insulation combined with thermal mass installations can work with passive heating and cooling strategies to further decrease energy needs (Glossner, Adhikari \& Chapman, 2015; Scheatzle, 2006). With regards to structural assemblies, studies states that wood is one of the oldest and most sustainable materials for building as it is abundant, locally available and versatile (Araujo et al., 2016). Concrete forms and bricks can also be efficient structural materials, providing durable stability and opportunities as a thermal mass (Scheatzle, 2006).

\section{Introduce Energy Efficient Systems + Technology}

For conventional buildings, only $5-15 \%$ of the total building life-cycle cost is accounted for in the design and construction phase, and therefore the operation of the building accounts for most of the energy and consumption of resources over time. Some of the more popular new technologies for heating and cooling involve ultra-efficient heat pumps, natural gas and low-cost gas heat pumps, which can reduce home energy consumption by more than $30 \%$ (U. S. Department of Energy, N.D.). Combining efficient fuel-burning heat-generation methods with advanced insulation, high-efficiency window assemblies, and passive technologies can be very efficientreducing heat loss through the envelope and loads on mechanical systems (Silverman \& Mydin, 2014). There are also opportunities to reduce water use with low-flow fixtures and rain water recycling systems, offsetting $80 \%$ of water used in the home (Prevost et al, 2015). 


\section{Design Innovation: A View from Paris}

In the following sections we provide specific case studies from the practice of Avenier Cornejo Architects in Paris, France, that illustrate the implementation of these design strategies in five award-winning projects. The agency has many achievements in the field of social housing and is a recognized leader in design innovation.

\section{Zac des Lilas, Paris}

Social housing with 240 units, 2013

Client: RIVP (Paris Public Housing Agency)

Architects: Avenier Cornejo \& Chartier-Dalix

Cost: $€ 19.9 \mathrm{~m}$

Surface $9,300 \mathrm{~m}^{2}(\mathrm{SHON})$

HQE Labels: Paris Climate Plan, BBC Effinergie

H \& E Profile A

Profile: Performance Option

The housing development includes a hostel for immigrants, a hostel for young workers, a day care on the ground floor, as well as communal facilities. Located in the 20th arrondissement of Paris, the building is part of an area undergoing immense change including the beltway and the art-house cinema. The structure's homogeneity is due to the building's symbolic nature; it is visible from the area's new public spaces. The high density of the services offered translates into very carefully planned housing, offset by two breaks, which divide the building both horizontally and vertically. The third floor is open, providing a view of Paris and a common space for residents. The vertical rift, a source of light for the circulation facing the street, offers a visual link between hostel life and the area around it (Refer to Figures 15.1 and 15.2).

The Hostel's common amenities (media centre, sport hall, group kitchen) are located on one level (third floor). This area offers the residents of the two hostels the possibility to "live together." It allows them to get to know each other as they participate in different activities. The goal of mixing diverse groups together responds to the desire to bring people from different walks of life under one roof. The vertical rift hollows out the building, creating areas for people to come together and relax on each floor. The Day Care is located on the ground floor facing south. The rooms enjoy generous light and extend to the outside play areas. An aerial canopy made from a light metallic mesh covers the play areas, giving a sense of protection without blocking any light. A combination of delicate and rustic plants borders the playground. The Flats are compact $18 \mathrm{~m}^{2}$ with $2 \times 2 \mathrm{~m}$ windows for each studio, designed to maximize the use of the space and to provide a flexible living area. Custommade furniture is designed by the architect. Shutters mean the kitchenette can be closed off; there are two sleeping options - a pull-out bed or a trundle bed. A bench and wardrobe maximize space and comfort, while the bathrooms are naturally lit using a light well.

The entire building is covered with a homogeneous skin. It is cladded in brick, which is longlasting and easy to maintain. The bricks are handmade and placed using a square edged joint cut. This semi-industrial manufacturing method gives the brick infinite shades in its anthracite tones. In order to bring out the sensual pleasure of this material, the two caesuras are dressed in copper. The setback of floors 7-9 allows space for some small terraces in varnished aluminum.

Two wind turbines installed on the roof supply energy to the day care during the day and the hostel at night. This choice of energy supply, still in its infancy in an urban setting, is particularly justified here. The building is located in an elevated position and is in a wind corridor. Solar panels located on the roof meet $30 \%$ of the building's energy needs. 

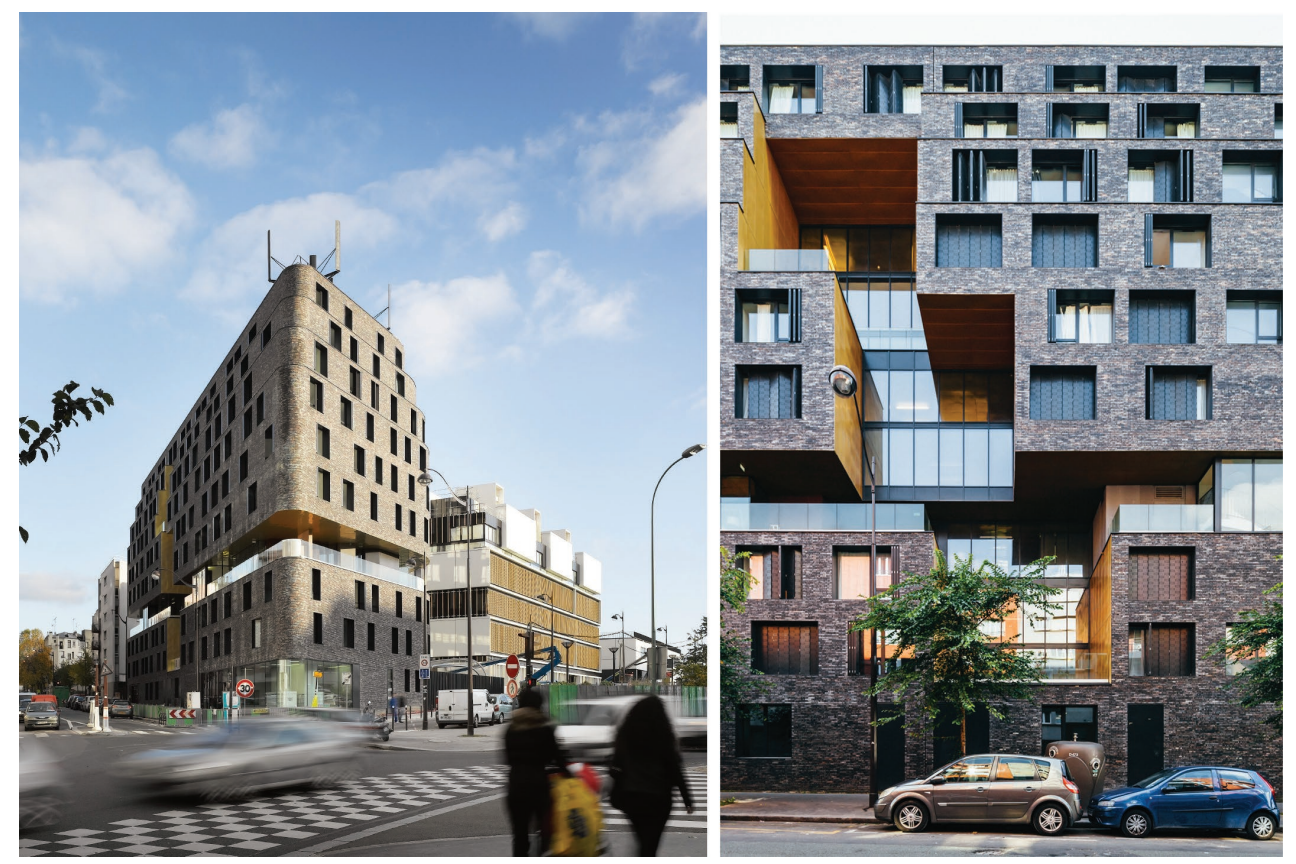

FIGURE 15.1 Porte des Lilas Urban Development Zone.

Source: Avenier Cornejo Architects.
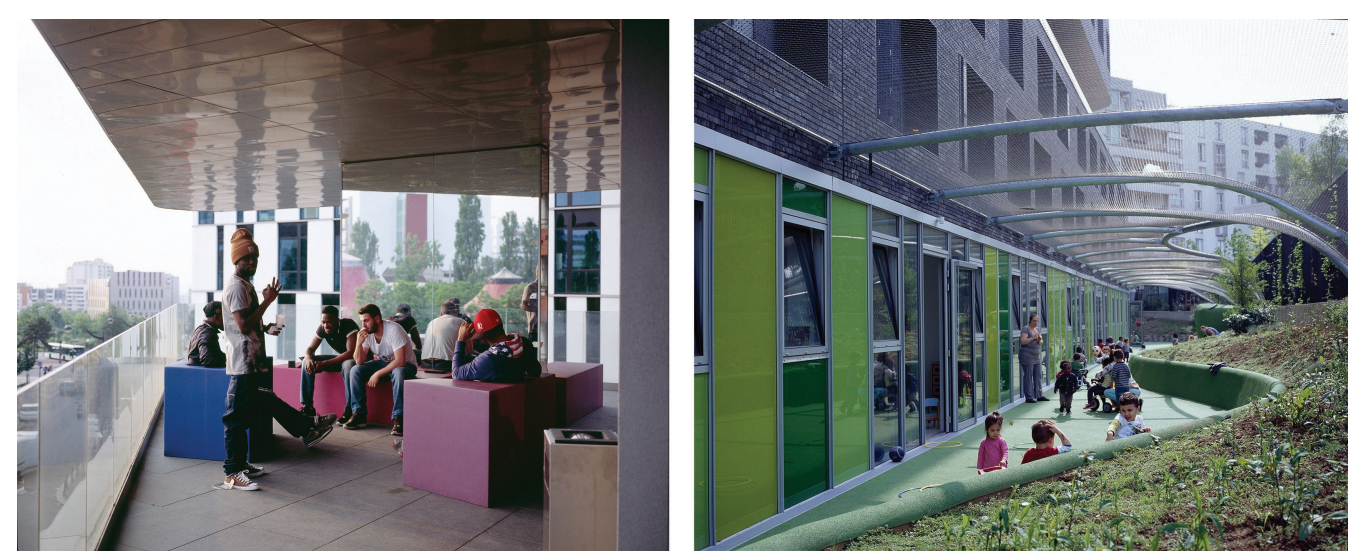

FIGURE 15.2 Porte des Lilas Young Workers' Hostel and Day Care.

Source: Avenier Cornejo Architects.

\section{Rue Saint-Maur, Paris}

Social housing with 14 units and activity space, 2016

Client: elogie-SIEMP

Architects: Avenier Cornejo

Labels: HQE Plan climat de Paris, BBC Effinergie, H\&E Profil A Option Performance, RT2012

The social housing apartments at 179 rue Saint-Maur are located on the site of a former wellknown space "Nine Billiards". The unhealthy conditions of the structure forced a demolition and reconstruction of the building. Each element of the project reinterprets the dense and 
complex "faubourien" fabric in order to blend in the existing urban landscape, while emphasizing originality that creates the real identity of the project. The building takes advantage of the narrow plot to develop into a compact and efficient six-storey high shape. The front façade integrates with the street by a raw and minimalist materiality: stained concrete that unfolds from the sidewalk up to the roof curb. A subtle series of diagonal lines cuts the façade in three sections to align with adjacent buildings. This is not just a symbolic gesture to the urban landscape, but a spatial synergy with the existing context (Refer to Figure 15.3).

The plot has a small garden of $47 \mathrm{~m}^{2}$ facing south. Each of the 14 units, ranging from studios to 3-bedroom apartments, is flooded with light and has a balcony with a unique place next to the kitchen. The balcony on the sixth floor offers a frame over the Paris rooftops and grants an unexpected one-on-one with the city. The design orients the living room and the kitchen towards the garden, while bedrooms face Rue Saint-Maur. The interior of the apartments is atypical and contradicts the rigidity of the façade by integrating non-standard, daring elements: rounded walls in the living room, folded wall sections and square openings where a wall meets the ceiling, thus creating a contemporary composition of forms that interact with the natural light.

Each architectural element is a detail treated with attention: large casement windows in every room, opening from floor to ceiling in each living room and kitchen, full-height closets with customized hinged doors and perforated louvered shutters along the windows facing the garden. The materials used are of good quality: solid wood windows and enamel sinks.

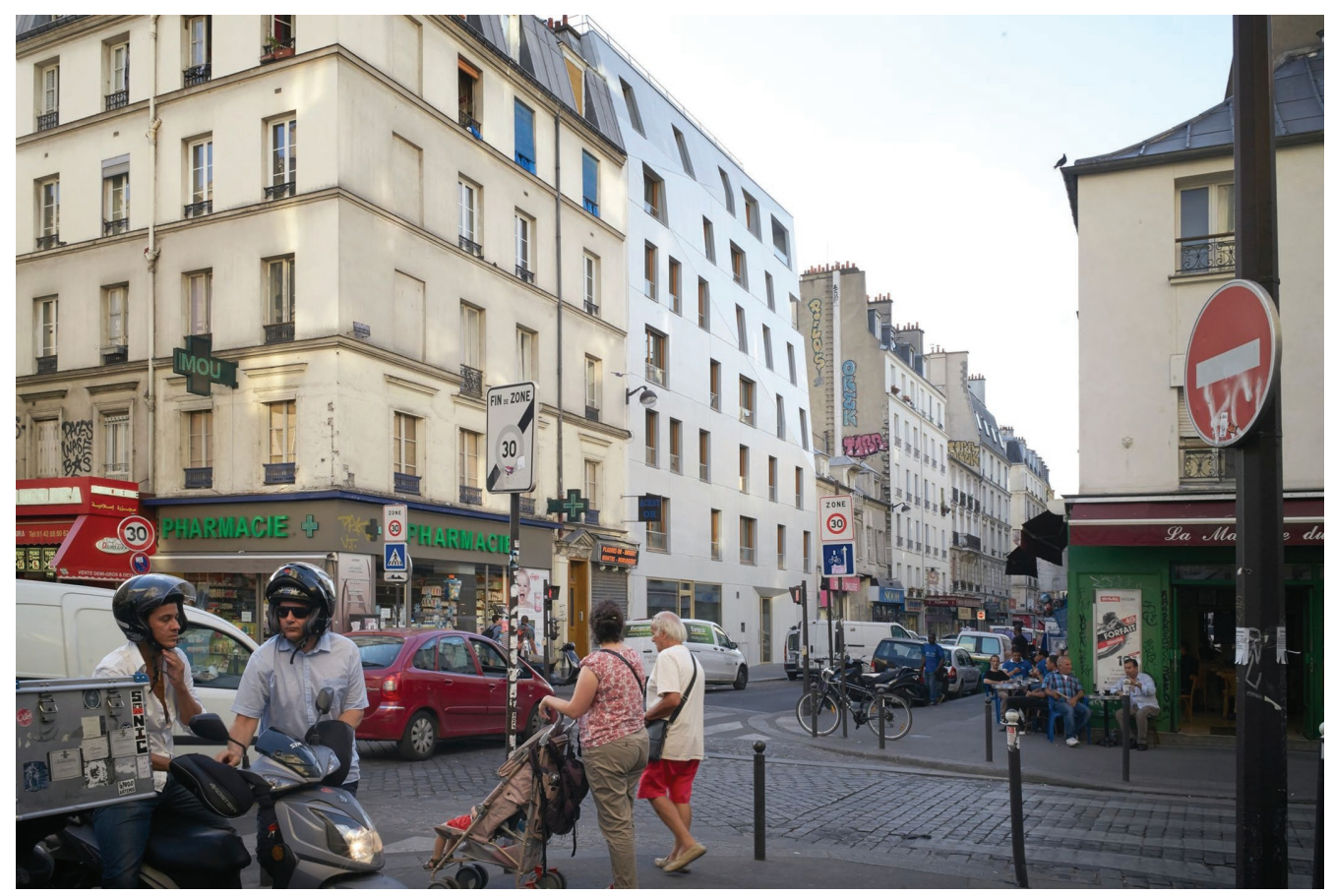

FIGURE 15.3 Social Housing: A New Version of the Faubourien Style.

Source: Avenier Cornejo Architects. 


\section{Rue Bonnet Clichy: The Ambivalence of a Beacon to Reconnect a City}

Social housing with 38 units, 2016

Client: Efidis

Architects: Avenier Cornejo

Surface: $2,900 \mathrm{~m}^{2}$ (SHON)

Labels: HQE BBC Effinergie

H\&E Profil A, RT2012

The 38 social housing units at 10/12 rue Bonnet in Clichy-la-Garenne completed for Efidis are located at the doorstep of Paris, along the périphérique beltway. At the edge of the capital and its inner suburbs, the development looks towards the Clichy-Batignolles district and the new regional court de Renzo Piano. Inside and out, the design approach embodies a strategy that eliminates borders in the city through a building that connects two different urban entities towards a common future (Refer to Figures 15.4).

The multifamily housing sets a unique standard of a new neighbourhood, which will mark the threshold of Clichy-la-Garenne, aptly named "ZAC entrance of the city". It can reach ten stories, allowing the building to make a statement and overlook a large part of its surroundings. The southeast façade on perforated metal vibrates with its louvered shutters and echoes the activity of the city and the speed of the périphérique.

The project responds to the composite fabric of Clichy-la-Garenne, starting a dialogue with its brick landmarks. The northwest and southwest façades feature a dark red 'Lucca' brick full with vivid joints. To render this brick façade even more vibrant, an array of ornamentation connects two expressions of the city, that of the capital and that of the suburbs. A motif in Art
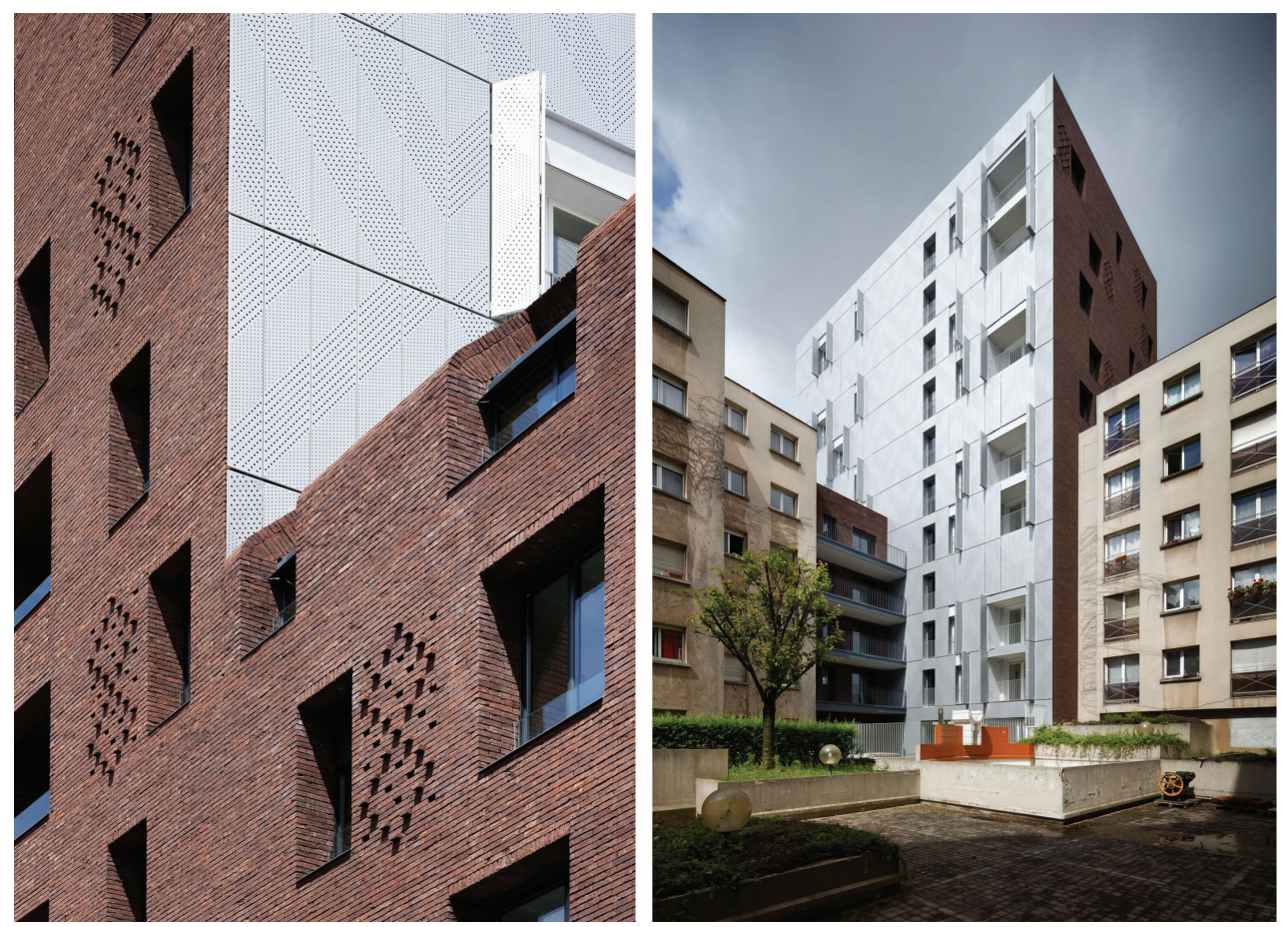

FIGURE 15.4 Social Housing in Paris, Rue Bonnet.

Source: Avenier Cornejo Architects. 
Deco tones, two crossing diamonds, originates from the overhanging and recessing of brick headers on one side, and through large-scale metal perforations on the other. On the ground floor facing the street, the façade alternates large spans of brick with glass-covered surfaces such as the entrance and the commercial space. The wall spacing between bricks creates a feeling for intimate spaces and ensures ventilation while maintaining privacy allowing glancing in from certain angles. The hall acts as a transition between the exterior and the interior by a view from the sidewalk into the garden.

The units also entertain this ambiguity of rapport to the city by opening to the heart of the lot through balconies and loggias, which hide behind the perforated metal, or through loggias cut into the brick facing the street. Each apartment has a double exposure transforming the natural light. This also multiplies the viewpoints on an ever-changing city that extends its borders to regenerate its identity.

\section{Rue de Charenton, Paris 12}

BEPOS building with 22 dwellings and business premises, 2019

Client: Habitat Social Français

Architects: Avenier Cornejo

Surface: $1,795 \mathrm{~m}^{2}$ (SDP)

Labels: HQE BEPOS Effinergie 2013, Certified NF Habitat HQE (eight stars), RT2012, Climate Plan of the City of Paris
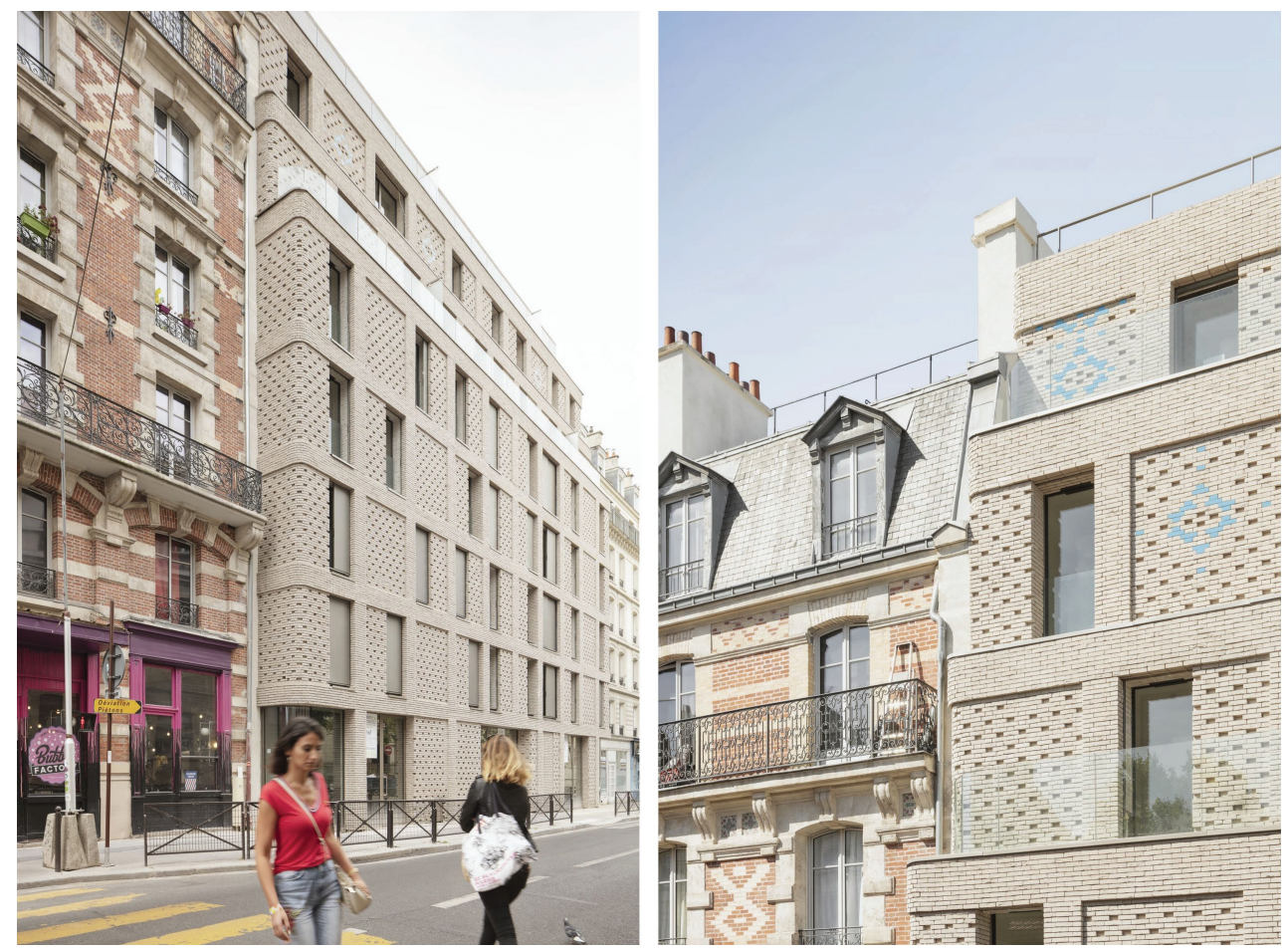

FIGURE 15.5 BEPOS Energy Efficient Social Housing, Paris.

Source: Avenier Cornejo Architects. 
Rue de Charenton is one of the oldest and longest in Paris with a very diverse streetscape. The site is close to Paris City Hall, and a design competition by Habitat Social Français required a replacement of the existing structure. Each element of the project advances the vision for 22 social housing units with sustainability features that reinterpret the unique urban fabric while creating a real identity of the project (Refer to Figures 15.5).

Our approach for the design of "BEPOS", which produces more energy than it consumes, was to think first of maximizing the natural efficiency of the site. The team proposed a compact U-typology building, with a large frontage on the garden, facing southwest. Building massing capitalizes on three successive withdrawals on the street side as well as on overflow on the road carried over from the existing structure. The brick cladding of the façade ensures coherence and a harmonious relation with the immediate environment. The sun-drenched garden façade vibrates with perforated aluminum shutters. This system allows thermal regulation and intimacy of the terraces and interiors. The two gable walls outline a geometric design thanks to bricks of different nature (glazed, enamel blue, glass). Larger apartments have natural ventilation, private outdoor area, terraces or loggias.

The entrance extends the continuity of Rue Bignon. Framed by the windows of the business premises and common areas, it creates a "visual breakthrough" to the garden. A garden is located in heart of islet, a cool and natural place in balance with the housing. Selected vegetation, left free, allows easy and occasional maintenance.

\section{Rue Dareau, Paris 14}

Student Housing \& Music Facilities

Status: in progress

Client: RIVP

Architects: Avenier Cornejo

Surface: $2,857 \mathrm{~m}^{2}$ (SDP)

Labels: HQE Label E + C level E2C1, Effinergie +

The Ourcq Canal, steeped in history, is a testimony to a continuous evolution. It has precious historical buildings, while it continues to evolve to adapt to the needs of urban life. The three buildings, property of ZAC Grands Moulin de Pantin, built by Emerige and Semip, are located on the canal. The design approach respected the exceptional location and its industrial heritage, while capitalizing on contemporary architecture for the layout of the buildings. The programme includes a cultural/music facility for the association La Sirène and 50 student housing units at 18-20 rue Dareau. One of the features of the project is the creation of a breakthrough, visible from the square. It acts as a breath, a visual extension of the plant party, extending the island's heart. This opening creates a unique sense of place, integrating the three buildings and a garden of $878 \mathrm{~m}^{2}$. An interior and exterior link is made possible with a large number of terraces, loggias and balconies (Refer to Figure 15.6).

The project is conceived as a homogeneous whole - sober and refined. Each of the brick buildings has a specific hue that identifies them. The windows as well as the shutters are in metalcoloured aluminium, as well as the guards and the underside of the balconies. In the same spirit as the brick, a metallic shade identifies each frame. Strong elements emerge to animate the façades of the project following the orientation and bringing a reading of district and an urban visibility. The green roofs, treated as a "5th façade", preserve the visual comfort of the residents. The greening of the roof promotes landscaping and helps to fight against the heat island effect. These roofs also provide a refuge for insects and birds and fight against fragmentation of the environment. The inertia 


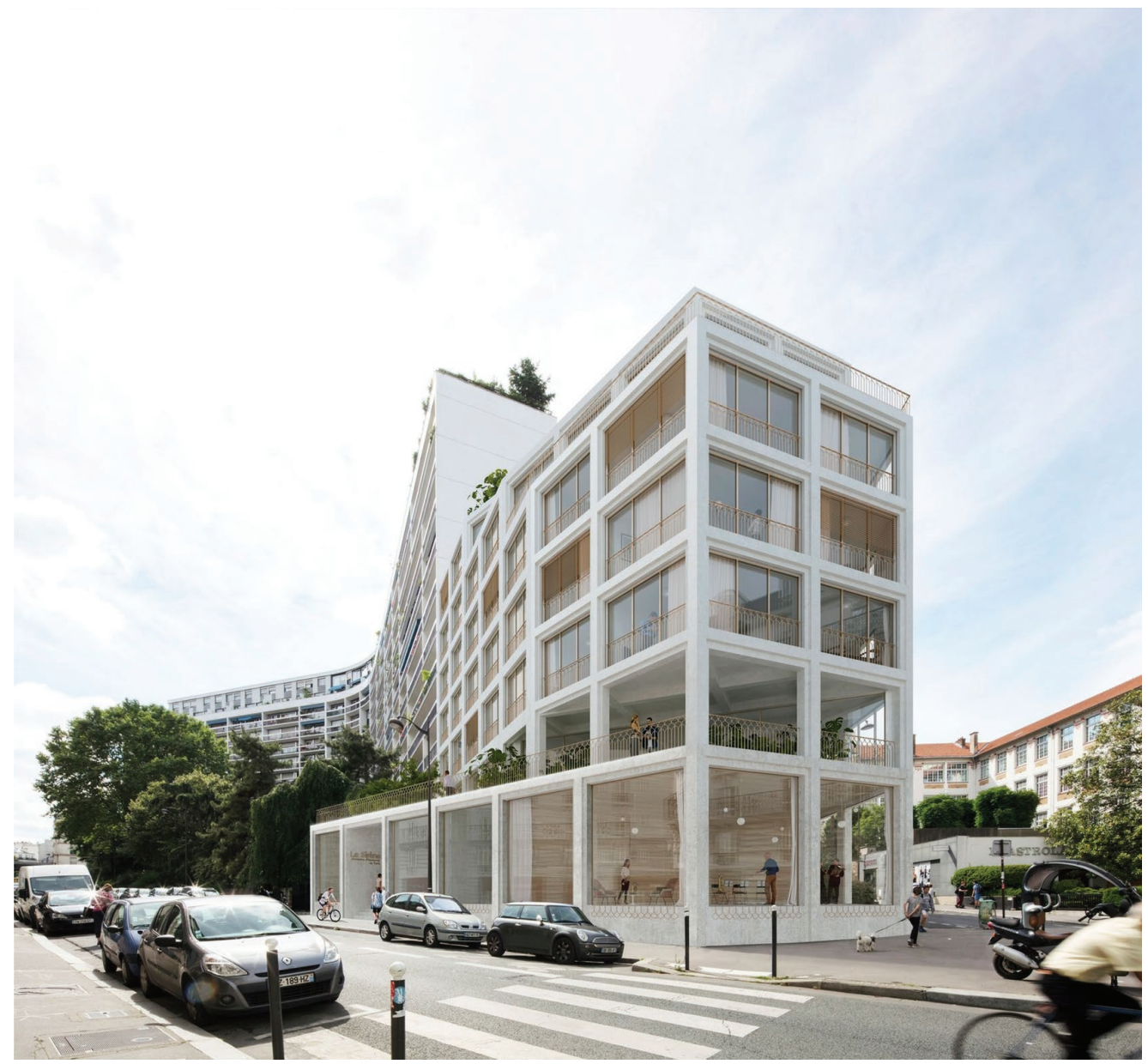

FIGURE 15.6 Student Social Housing and Music Facilities, Paris.

Source: Avenier Cornejo Architects.

of the earth mass makes it possible to manage rainwater and to protect the building against large temperature variations. It greatly increases the insulation of the roof, usually a source of heat losses.

This design approach leads to transversal approaches that mix scales. In a journey from the general to the particular, the morphology, the materiality, the spatiality, the systems and the uses are considered. This approach favours simplicity and architectural quality in order to be part of a sustainable strategy.

\section{Concluding Comments}

Social housing projects in Paris are embedded in a dense interconnected urban environment, often close to the historic city centre. The planning and design requirements are complex and the myriad approvals and community consultations are challenging to navigate. Design competitions are a standard process to identify the best and the most innovative solution for new social housing developments in the context of urban regeneration. The new sites become an important urban portal for social integration and perform a role of a hub within the Parisian system of interconnected neighbourhoods; they work from the inside-out to connect people to 
jobs, parks and community spaces and reinforce urban, social and cultural transfer (Gausa et al., 2019). Resonating with neighbourhood buildings and streetscapes, the projects prioritize urban dialogue, elegance in building massing and use of materials in a sensitive way. Schools, day care, community spaces and pocket parks often become part of the social housing projects. The goal is to create dynamic movement and rhythm associated with the rich architecture of the past in the immediate environment, optimization of planning rules and design with sustainability and environemntal performance in mind. This design puzzle often integrates the layering of a variety of strategies to enhance sustainability - from the quest for compact form and housing diversity, to incorporation of green roofs, grey water heat recovery, rainwater harvesting, solar energy and solar filters in the new addition to the historic landscape. Excellence by design is essential for the long-term success of social housing and its good vibrations in the Parisian neighbourhood.

\section{References}

Baker, D., and Patel, A. (2015). 11 Strategies for Building Community with Affordable Housing. Urban Land Magazine, February 13. Washington, DC: Urban Land Institute.

Canadian Mortgage and Housing Corporation. (2016). Sustainable Building: A Materials Perspective. Retrieved from http://aanb.org/wp-content/uploads/2016/08/sustainable_materials.pdf

Evans, D., and Beck, J. (2005). Good Design: The Best Kept Secret in Community Development. New York: Local Initiatives Support Corporation.

Gausa \& Raveau Actarquitectura and Avenier-Cornejo Architects. (2019). Good Vibrations. Clichy Batignolles. Paris: Gausa \& Raveau Actarquitectura and Avenier-Cornejo Architects.

Glossner, S. J., Adhikari, S., and Chapman, H. (2015). Assessing the Cost Effectiveness of LEED Certified Homes in Kentucky. Journal of Technology Studies, 41(1), 10-19.

Martty, M. (2015). The Difference between Green and Sustainable. Sourceable. Retrieved from https://sourceable.net/difference-green-sustainable/

New Jersey Institute of Technology, Center for Architecture and Building Science Research (NJIT). (2003). Bringing the Power of Design to Affordable Housing: An Evaluation of the Affordable Housing Design Advisor. Washington, DC: U.S. Department of Housing and Urban Development, Office of Policy Development and Research.

New York City Design/AAA Housing. (2018). Designing New York: Quality Affordable Housing. New York: NYC Public Design Commission City Hall.

Praznik, M., Butala, V., and Zbašnik-Senegačnik, M. A. (2014). Simple Method for Evaluating the Sustainable Design of Energy Efficient Family Houses. Strojniski Vestnik / Journal of Mechanical Engineering [serial online], 60(6), 425-436.

Prevost, G., Baetz, B. W., Razavi, S., and El-Dakhakhni, W. (2015). Retrofitting Suburban Homes for Resiliency: Design Principles. Journal of Urban Planning \& Development, 141(3), 1-10.

Rothrock, H. (2014). Sustainable Housing: Energy Evaluation of an Off-Grid Residence. Energy E Buildings, 85287-85292.

Scheatzle, D. (2006). Combining Radiant and Convective Systems with Thermal Mass for a More Comfortable Home. ASHRAE Transactions, 112(1), 253-268.

Silverman, N., and Mydin, A. O. (2014). Green Technologies for Sustainable Building. Acta Technica Corvininesis - Bulletin of Engineering, 7(3), 87-94.

Tsenkova, S. (2014). A Tale of Two Cities: Resilience of Social Housing in Vienna and Amsterdam [Krisenfestigkeit der sozialen Wohnungssektoren in Wien und Amsterdam]. In Amann, W., Pernsteiner, H., and Struber, Ch. (eds)., Wohnbau in Österreich in Europäischer Perspective. Vienna: Manz Verlag and Universitatsbuchhandlung, pp. 95-105.

Tsenkova, S. (2019). Social Housing on Trial: Institutions + Policy Design. Urban Research and Practice, $12(1), 1-6$. 